ized to one of the exercise programs or to the control condition, and differential effects on outcomes should be attributed to this factor. The children's fatness was reduced because of the exercise programs offered to those groups. Mediation analysis (ie, testing factors posited to be in the causal pathway) can suggest how those changes may have occurred based on contemporaneous, collinear data with varying precision. Mediation analyses on these data are in progress.

As expected, puberty (ie, thelarche or gonadarche stage) was a predictor in the insulin resistance models (insulin area under the curve, $P<.001$; fasting insulin, $P<.001$; Matsuda index, $P=.002$ ). The adrenarche variable was not significant in any model. At the request of Short, we conducted an analysis of the interaction of thelarche or gonadarche stage (classified as Tanner I, II, or III and above) with the group $\times$ time interaction in the insulin resistance models, adjusting for cohort, sex, and race. An interaction was detected only for fasting insulin, such that differential change from baseline to posttest between exercise groups and control was detected only in Tanner stage III or above. In more developed children, similar decreases in fasting insulin were seen in the low-dose (adjusted mean difference, $-18.2[95 \% \mathrm{CI},-25.8$ to -10.6$] \mu \mathrm{U} / \mathrm{mL}$ ) and high-dose $(-15.8$ [95\% CI, -23.0 to -8.5$] \mu \mathrm{U} / \mathrm{mL})$ exercise groups (each $P<.001$ vs the control group). Thus, more developed children might be more responsive to exercise. However, of 3 insulin resistance indicators, only 1 showed evidence of pubertal moderation. These exploratory analyses provide scant support for the hypothesis that pubertal stage affects the benefits of aerobic training in obese children. Conclusions should be tempered by the exploratory nature of these additional analyses.

Catherine L. Davis, PhD

Jennifer L. Waller, PhD

Norman K. Pollock, PhD

Author Affiliations: Departments of Pediatrics (Drs Davis and Pollock) (cadavis @georgiahealth.edu) and Biostatistics (Dr Waller), Medical College of Georgia, Augusta.

Conflict of Interest Disclosures: The authors have completed and submitted the ICMJE Form for Disclosure of Potential Conflicts of Interest and all 3 reported receiving grants from the National Institutes of Health.

1. Ferguson MA, Gutin B, Le NA, et al. Effects of exercise training and its cessation on components of the insulin resistance syndrome in obese children. Int J Obes Relat Metab Disord. 1999;23(8):889-895.

2. Owens S, Gutin B, Ferguson M, Allison J, Karp W, Le NA. Visceral adipose tis sue and cardiovascular risk factors in obese children. J Pediatr. 1998;133(1): 41-45.

3. Short KR, Pratt LV, Teague AM, Man CD, Cobelli C. Postprandial improvement in insulin sensitivity after a single exercise session in adolescents with low aerobic fitness and physical activity [published online July 23, 2012]. Pediatr Diabetes. doi:10.1111/j.1399-5448.2012.00900.x.

\section{Bisphenol A and Obesity in Children and Adolescents}

To the Editor: Dr Trasande and colleagues ${ }^{1}$ concluded that "Urinary [bisphenol A] BPA concentration was significantly associated with obesity in this cross-sectional study

134 of children and adolescents. Explanations of the association cannot rule out the possibility that obese children ingest food with higher BPA content or have greater adipose stores of BPA."

The authors also examined other environmental phenols and did not find an association with obesity, stating that "The absence of an association between body mass/ obesity and levels of other environmental phenols argues for a specificity of association."

The problem is that BPA is a lipophilic compound and would have a propensity to be stored in fat, leading to an increased amount in the urine of obese children. Bisphenol A has a water solubility of 120 to $300 \mathrm{mg} / \mathrm{L}$ (practically insoluble in water). ${ }^{2,3}$ On the other hand, phenols as a group have a great range in solubility. For example, phenol is soluble in water at $83 \mathrm{~g} / \mathrm{L} .{ }^{3}$ The authors do not discuss the solubility of the other phenol compounds, which would have to be comparably lipophilic to draw the conclusion that the association is specific. In addition, the study was limited by only measuring urine concentrations of BPA, which may not reflect the serum level.

It was appropriate for Trasande et $\mathrm{al}^{1}$ to suggest that obese people may have higher stores of BPA in their fat. If this is indeed the case, then obesity would result in higher levels of BPA in the urine and would not be the cause of obesity but rather the result.

Robert L. Brent, MD, PhD, DSc

Author Affiliation: Department of Pediatrics, Jefferson Medical College, Philadelphia, Pennsylvania (rbrent@nemours.org).

Conflict of Interest Disclosures: The author has completed and submitted the ICMJE Form for Disclosure of Potential Conflicts of Interest and reported being a consultant for the Food and Drug Administration, Centers for Disease Control and Prevention, and National Institutes of Health; providing expert testimony in vaccine litigation as a defense expert for the US government; and receiving travel expenses for meetings of the Teratology Society, Institute of Medicine, National Council for Radiation Protection, The Fetus as a Patient, Health Physics Society, and International Academy of Perinatal Medicine from his university account.

1. Trasande L, Attina TM, Blustein J. Association between urinary bisphenol A concentration and obesity prevalence in children and adolescents. JAMA. 2012; 308(11):1113-1121.

2. Staples CA, Dorn PB, Klecka GM, O'Block ST, Harris LR. A review of the environmental fate, effects, and exposures of bisphenol A. Chemosphere. 1998; 36(10):2149-2173

3. Merck \& Co Inc. Phenol. In: The Merck Index. 14th ed. Rahway, NJ: Merck; 2006.

In Reply: In our analysis of data from the 2003-2008 National Health and Nutrition Examination Survey (NHANES), we found associations of urinary BPA (but not other chemically similar environmental phenols) with body mass index $z$ score and obesity in children and adolescents, whether the urinary concentration was categorized in quartiles or analyzed as a continuous variable. Dr Brent asserts that we failed to account for the lipophilic nature of BPA and therefore its propensity to be stored in the adipose tissue of obese individuals (especially compared with other environmental phenols), invalidating our use of their urinary concentrations as tests of specificity.

@)2013 American Medical Association. All rights reserved. 
To reinforce his assertion, Brent suggests that BPA has low water solubility. However, one of his citations actually states that BPA is "moderately soluble" in water. ${ }^{1}$ More recent reviews by the World Health Organization estimate BPA solubility in water to be 0.5 to $1.3 \mathrm{mmol} / \mathrm{L} .{ }^{2}$ Furthermore, it is important to reflect on the metabolic transformation of BPA in humans. After dietary ingestion, BPA undergoes first-pass glycosylation in the liver, a process that increases its urinary excretion as water-soluble glucuronide conjugates. ${ }^{3}$ The NHANES analytic method used to measure BPA quantifies total (conjugated and unconjugated) BPA. ${ }^{4}$

The lipophilicity of BPA compared with the other environmental phenols can be evaluated by comparing the chemicals' octanol and water partition coefficients - the higher the coefficient, the more lipophilic the compound. Compared with benzophenone-3, triclosan, and 4-tertoctylphenol, BPA has a much lower partition coefficient $\left(\mathrm{K}_{\mathrm{ow}}, 2.2-3.4\right),{ }^{2}$ and therefore is less likely to be stored in fat than the other phenols. Thus, it was appropriate to examine associations of urinary BPA alongside urinary concentrations of other environmental phenols, as we did in our study.

Brent's comment presents an opportunity to reinforce that our specificity tests have limits intrinsic to the crosssectional design. Absent controlled human experiments that intentionally provide BPA doses to individuals and examine weight gain, observational, longitudinal studies are needed to examine whether BPA may be associated with obesity or whether obese children simply excrete more BPA. If further research reveals that the latter is more likely, our study raises concerns that obese children may be susceptible to adverse neurodevelopmental and respiratory effects that have been associated with BPA exposure in children. ${ }^{5,6}$

Leonardo Trasande, MD, MPP

Teresa M. Attina, MD, PhD, MPH

Jan Blustein, MD, PhD

Author Affiliations: Department of Pediatrics, New York University School of Medicine, New York (Drs Trasande and Attina) (leonardo.trasande@nyumc.org); and New York University Wagner School of Public Service, New York (Dr Blustein). Conflict of Interest Disclosures: The authors have completed and submitted the ICMJE Form for Disclosure of Potential Conflicts of Interest and none were reported.

1. Staples CA, Dorn PB, Klecka GM, O'Block ST, Harris LR. A review of the environmental fate, effects, and exposures of bisphenol A. Chemosphere. 1998; 36(10):2149-2173.

2. Doerge DR, Fisher JW. Background paper on metabolism and toxicokinetics of bisphenol A: FAO/WHO expert meeting on bisphenol A (BPA). http://www.who .int/foodsafety/chem/chemicals/4_metabolism_and_toxicokinetics.pdf. Accessed October 25, 2012

3. Völkel W, Colnot T, Csanády GA, Filser JG, Dekant W. Metabolism and kinetics of bisphenol a in humans at low doses following oral administration. Chem Res Toxicol. 2002;15(10):1281-1287.

4. US Centers for Disease Control and Prevention. NHANES 2003-2004: environmental phenols (L24EPH_C). http://www.cdc.gov/nchs/nhanes /nhanes2003-2004/L24EPH_C.htm. Accessed November 5, 2012.

5. Braun JM, Kahn RS, Froehlich T, Auinger P, Lanphear BP. Exposures to environmental toxicants and attention deficit hyperactivity disorder in US children. Environ Health Perspect. 2006;114(12):1904-1909.

6. Spanier AJ, Kahn RS, Kunselman AR, et al. Prenatal exposure to bisphenol A and child wheeze from birth to 3 years of age. Environ Health Perspect. 2012; 120(6):916-920.

C2013 American Medical Association. All rights reserved.

\section{Strategies for Tailoring Asthma Treatment in Adults}

To the Editor: The Best Adjustment Strategy for Asthma in the Long Term (BASALT) trial conducted by Dr Calhoun and colleagues ${ }^{1}$ compared 3 strategies for tailoring asthma treatment in adult patients, including adjustment of inhaled steroids based on physician assessment, exhaled nitric oxide, and day-to-day symptoms. The data showed that the exhaled nitric oxide or daily symptom strategies were not superior to physician assessment with regard to treatment failure.

The BASALT trial is an example of an asthma treatment algorithm study. ${ }^{2}$ These kind of studies aim to improve clinical outcome by tailoring treatment with existing drugs based on predefined levels of a quantitative disease marker. The design of such trials is pivotal, including choices regarding the patient population, definition of the clinical end point, clinical room for improvement, selection of the disease marker, discrete levels of the marker leading to treatment changes, and dose adjustments of the drug. ${ }^{3}$

The BASALT trial investigators made several choices that may have affected the results. Exhaled nitric oxide is now not the biomarker of choice-sputum eosinophils are. ${ }^{4} \mathrm{How}-$ ever, this is based on data from a recent meta-analysis and the trial was designed more than 5 years ago. Also, the BASALT trial investigators chose to enroll patients with mild asthma who were well controlled with low-dose inhaled corticosteroids at baseline. ${ }^{1}$ This selection of well-controlled patients may have limited the external validity of the study and its generalizability to less well-controlled patients.

Control of these patients at baseline must have been determined by a physician assessment strategy, which is the standard clinical procedure. Hence, the patients represent a subgroup of patients with asthma and apparently good adherence who were probably doing well on physicianguided care prior to study inclusion. Is it surprising that the same patients also did well by physician-guided care during the trial?

The present study does not answer the question of whether the biomarker or daily symptom strategies are superior to physician assessment in patients with uncontrolled asthma at baseline. The latter group of patients showed the largest benefit by biomarker-guided treatment in a previous study. ${ }^{5}$ Adding novel management strategies in patients for whom the physician already knows best is not necessary. Such strategies may be needed for patients when the physician's assessment fails.

Peter J. Sterk, MD, PhD

Jacob K. Sont, PhD

Author Affiliations: Department of Respiratory Medicine, Academic Medical Centre at the University of Amsterdam, Amsterdam, the Netherlands (Dr Sterk; p.j.sterk@amc.nl); and Department of Medical Decision Making, Leiden University Medical Centre, Leiden, the Netherlands (Dr Sont).

Conflict of Interest Disclosures: The authors have completed and submitted the ICMJE Form for Disclosure of Potential Conflicts of Interest. Dr Sterk reported receiving a grant (Innovative Medicines Initiative) from the European Union, the European Federation of Pharaceutical Industries, and Associations 